\title{
Publisher Correction: RdDM-independent de novo and heterochromatin DNA methylation by plant CMT and DNMT3 orthologs
}

\author{
Rafael Yaari (1) ${ }^{1}$, Aviva Katz ${ }^{1}$, Katherine Domb ${ }^{1}$, Keith D. Harris ${ }^{1}$, Assaf Zemach $\mathbb{B}^{1}{ }^{1} \&$ Nir Ohad ${ }^{1,2}$
}

Correction to: Nature Communications https://doi.org/10.1038/s41467-019-09496-0, published online 08 April 2019.

The original version of this Article contained an error in Fig. 5, in which the evolutionary origin of DRM2 was incorrectly placed prior to the divergence between gymnosperms and angiosperms. The correct evolutionary origin of DRM2 should be in angiosperms. The correct version of Fig. 5 is shown here as Fig. 1, which replaces the incorrect version which is shown here as Fig. 2. In addition, in the "Percent methylation change" section of the Methods, Equation 1 was incorrectly given as:

$$
\frac{\mathrm{WT} \mathrm{mCHH}-\mathrm{cmt} m \mathrm{mHHWT} \mathrm{mCHH}}{\times} 100 \text { if } \mathrm{WT} \mathrm{mCHH}>\mathrm{cmt} \mathrm{mCHH}
$$

The correct form of Equation 1 is as follows:

$$
\frac{\mathrm{WT} \mathrm{mCHH}-\mathrm{cmt} \mathrm{mCHH}}{\mathrm{WT} \mathrm{mCHH}} \times 100 \quad \text { if } \mathrm{WT} \mathrm{mCHH}>\mathrm{cmt} \mathrm{mCHH}
$$

This has been corrected in both the PDF and HTML versions of the Article.

Published online: 06 June 2019

Open Access This article is licensed under a Creative Commons Attribution 4.0 International License, which permits use, sharing, adaptation, distribution and reproduction in any medium or format, as long as you give appropriate credit to the original author(s) and the source, provide a link to the Creative Commons license, and indicate if changes were made. The images or other third party material in this article are included in the article's Creative Commons license, unless indicated otherwise in a credit line to the material. If material is not included in the article's Creative Commons license and your intended use is not permitted by statutory regulation or exceeds the permitted use, you will need to obtain permission directly from the copyright holder. To view a copy of this license, visit http://creativecommons.org/licenses/by/4.0/.
\end{abstract}

(C) The Author(s) 2019

\footnotetext{
${ }^{1}$ School of Plant Sciences and Food Security, Tel-Aviv University, 69978 Tel- Aviv, Israel. ${ }^{2}$ The Manna Center Program for Food Safety and Security, Tel Aviv University, 69978 Tel-Aviv, Israel. These authors contributed equally: Rafael Yaari, Aviva Katz, Katherine Domb. These authors jointly supervised this work: Assaf Zemach, Nir Ohad. Correspondence and requests for materials should be addressed to A.Z. (email: assafze@tauex.tau.ac.il)

or to N.O. (email: niro@mail.tau.ac.il)
} 
a

A. thaliana

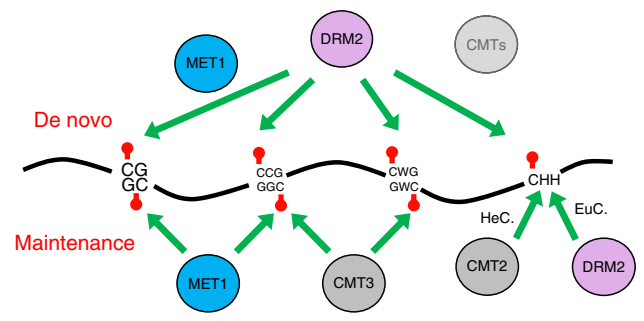

P. patens

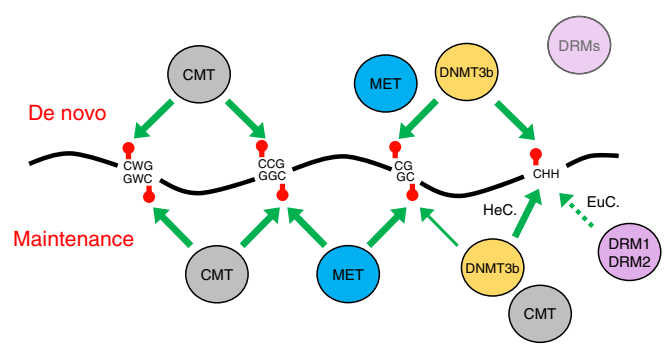

(CMT

b Green Algae Bryophytes Lycophytes Monilophytes Gymnosperms Angiosperms

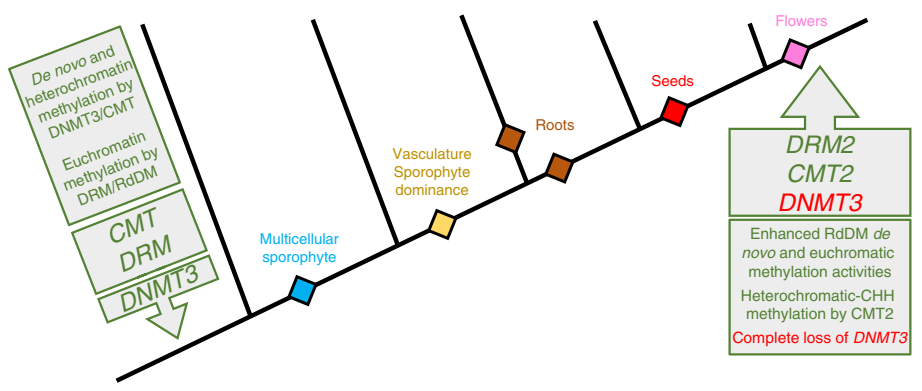

Fig. 1

a

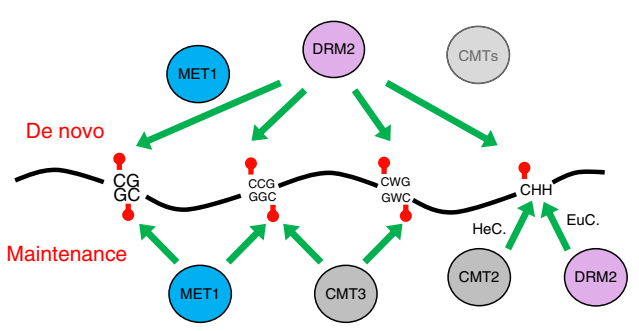

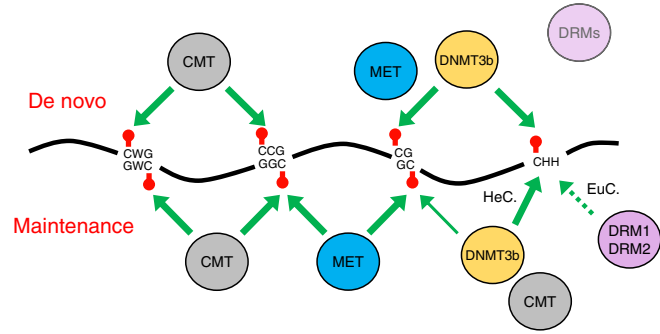

CMT

b Green Algae Bryophytes Lycophytes Monilophytes Gymnosperm Angiosperms

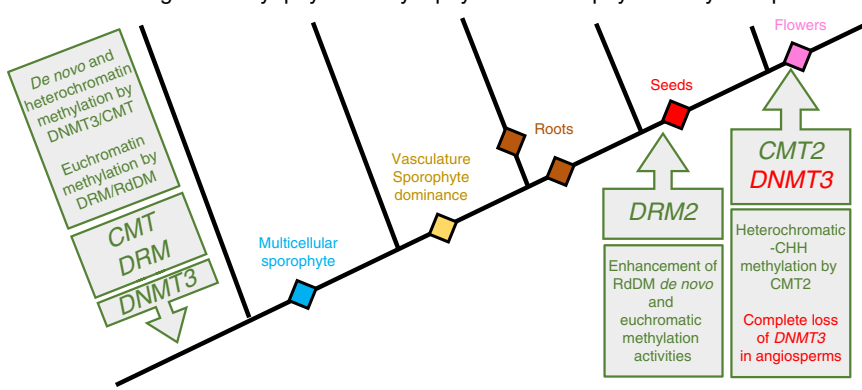

Fig.2 